\title{
Supporting SME information systems development using a structured method and tool for package selection
}

\author{
Little D, Gavin C J, Guenaoui DJ and Keller-Jackson C \\ Manufacturing Systems Research Group, The University of Huddersfield \\ The University of Huddersfield, Huddersfield, UK. \\ Telephone: $\quad 01484-472965$ \\ Fax: \\ $01484-451883$ \\ e-mail: d.little@hud.ac.uk
}

\begin{abstract}
The aim of the research was the development of a simple software specification method encapsulated within a software tool called SMEST (SME Support Tool) to assist SMEs in the specification of requirements process. Since this method must be aimed at the project manager with little knowledge of structured methods and tools, a workbook approach is adopted. The tool is focused on package selection rather than on bespoke software development because the second route is not normally practical in SMEs due to the inability of management to describe their requirements clearly and the expense involved in developing tailored software.
\end{abstract}

\section{Keywords}

Information systems, specification of requirements, package selection, SME.

\section{INTRODUCTION}

Nowadays the use of computer-based manufacturing technology and systems is essential if manufacturing organisations are going to compete effectively in 
domestic and world markets. However, previous research supported by the EPSRC has demonstrated the ineffectiveness of many manufacturing SMEs at the planning and scheduling of their work. Frequently their manufacturing information systems are not aligned in the support of their key business and management processes, with particular weaknesses in planning, scheduling and, consequently, execution.

This ineffectiveness is frequently due to the inadequate specification of user requirements and excessive reliance upon software vendors. Usually the structured methods and tools (SMT) used to model business processes and to generate the requirements specification are ignored by the SME who has neither the expertise nor the time to develop this. This is a mixed blessing because to a large extent such approaches and tools are inappropriate to SMEs

In addition, vendors of information systems software are commonly able to appreciate neither the particular problems associated with manufacturing nor with the operation of a typical SME. This lack of focus may be because the SME is not usually viewed as a 'good prospect' by the sales force.

The second part of this research project is targeted upon the development of a software specification method and support tool for manufacturing information systems package selection within an SME. SMEs rarely have the IT infrastructure and experience to exploit more formal structured methods and tools in the specification of requirements for their information systems and their reliance upon packaged solutions is unavoidable in the early phases of their systems development.

\section{OBJECTIVES}

The existence of an effective information system is important to manufacturing performance, but only when that the system is appropriate for the business. For instance, many of the software modules required in planning production in a company that produces fashion products will be different from that which suits a company producing complex capital equipment. This is because software should be a supporting tool rather than a business driver, although it is often sold as the latter.

The aim in this part of the research is to build upon previous work by the investigators in identifying the needs of the manufacturing system engineer or manager working in an SME as the target user. The main aim is the development of a simple software specification method, supported by a workbook and encapsulated within a software tool called SMEST (SME Support Tool) which can assist SMEs in both the specification of requirements and the package selection process. Since this method must be aimed at the manager with little knowledge of 
structured methods and tools, a workbook approach is adopted for the method. This method focuses on package selection rather than on bespoke software development because the second route is normally neither necessary or practical in SMEs in the early phases of their systems development.

\section{SME REQUIREMENTS SPECIFICATION AND PACKAGE SELECTION METHOD}

The method is to be used as a structured decision aid and is comprised of the first three modules (see figure 1 below) which lead to the generation of a requirements specification for package selection. The package selection process, itself, was seen to be outside the scope of this project because of the intensive requirement to populate the database with the details of a significant number of commercial packages.

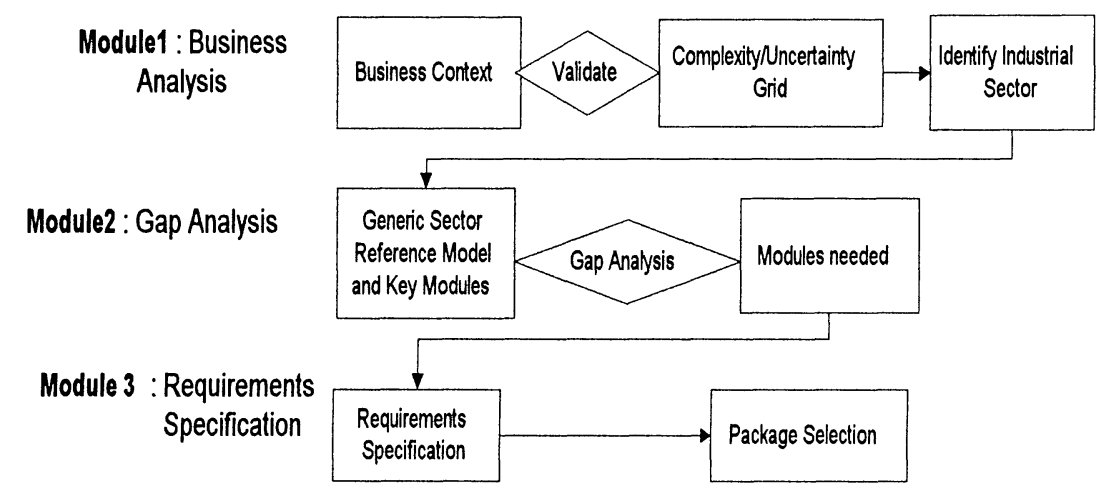

Figure 1: Description of the method

Module 1 - Business Analysis conducts an interactive business analysis in which the nature of company and its business context is determined. This allows the positioning of the company within one of four generic sectors indicated on a matrix or "Manufacturing Grid" based on complexity and uncertainty. Firstly, a series of questions is asked in order to determine the complexity of the business and the uncertainty of the processes and marketplace. These questions have been developed based upon extensive case study data conducted during the research and have been validated using questionnaires from over thirty respondents. Answering the questions positions the company within the complexity/uncertainty matrix. From this positioning, the strategic drivers for the 
business can be identified and, based upon reference models held within the tool, key information systems modules for that particular sector can be identified.

Module 2 - Gap Analysis: undertakes the comparison of existing information systems modules operating within the company against this information systems reference model to produce a gap analysis. The primary function of this is to identify key modules for the sector which are absent from the current systems.

Module 3 - Requirements Specification: for the modules identified by the gap analysis, a specification of requirements document is produced based on NCC guidelines. A template for requirements specification is provided for the user to complete.

This specification of requirements document can then be sent to vendors inviting them to reply in a standard format indicating how well their product fits the specification. This simplifies the selection of an appropriate packaged system by weighting the response from each vendor to the specification document.

The population of the support tool with product profiles for a range of popular packages with the ability to score each against the specification of requirements would be a logical extension to the workbook as a fourth module. However, the work required for this is beyond the resources of this project.

\section{SUPPORTING SOFTWARE TOOL AND WORKBOOK}

The supporting PC-based tool is based on a Windows 95 platform because this is necessary to support the Delphi development environment. The logic and the application rules of the method are implemented in an object-oriented programming environment called Delphi 2 . This uses a comprehensive library of visual components and a suite of rapid application design tools in order to create efficient Windows applications with a minimum of manual coding. Delphi was chosen because Delphi's integrated development environment (IDE) is ideal for writing Windows applications, with its visual editing controls, component library (including data base components and common Windows dialogues) and database engine.

The aim of the software tool is to help the user manager or project engineer to produce a more effective requirements specification based upon identified areas for improvement and then to select an appropriate software package that matches their business needs. It does this by following the steps set out in the workbook which adopts a step-by-step approach and assumes no expertise. A feature of the workbook is the extensive use of screens captured from the tool itself. 


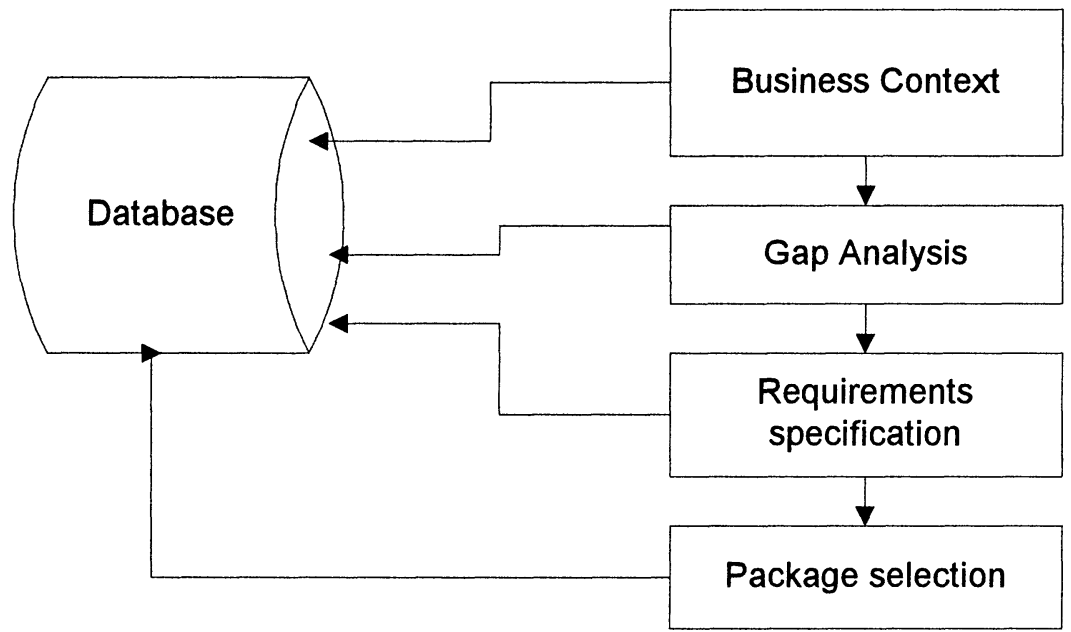

Figure 2: A simple Architecture of the system

The present menu structure of the tool is as follows:

Business Analysis: This will open the Business Analysis dialogue box where the user can open an existing project by clicking on the OK button or create a new one by clicking on the New button. The dialogue Create/Edit project contains two pages called complexity and uncertainty which present a range of questions (see figure 3):

Again by clicking on the Display Grid button, the Business Analysis Grid dialogue will pop-up using the answers of the complexity and uncertainty questions. (See figure 4).

Gap Analysis: The Gap Analysis dialogue box pop-up, asking the user to select the key modules which are absent from the current system provided from the available reference model.

Requirements Specification: The contents for the requirements specification dialogue box opens and presents the user with a template for requirements specification. By clicking the OK button, the editor Word for Windows will open. The tool used the OLE (Object Linking Embedded) Automation mechanism to open Word for Windows.

History: To view the history of the project, select the project to highlight it, and then click on the OK button. This opens the History dialogue box for that project. 


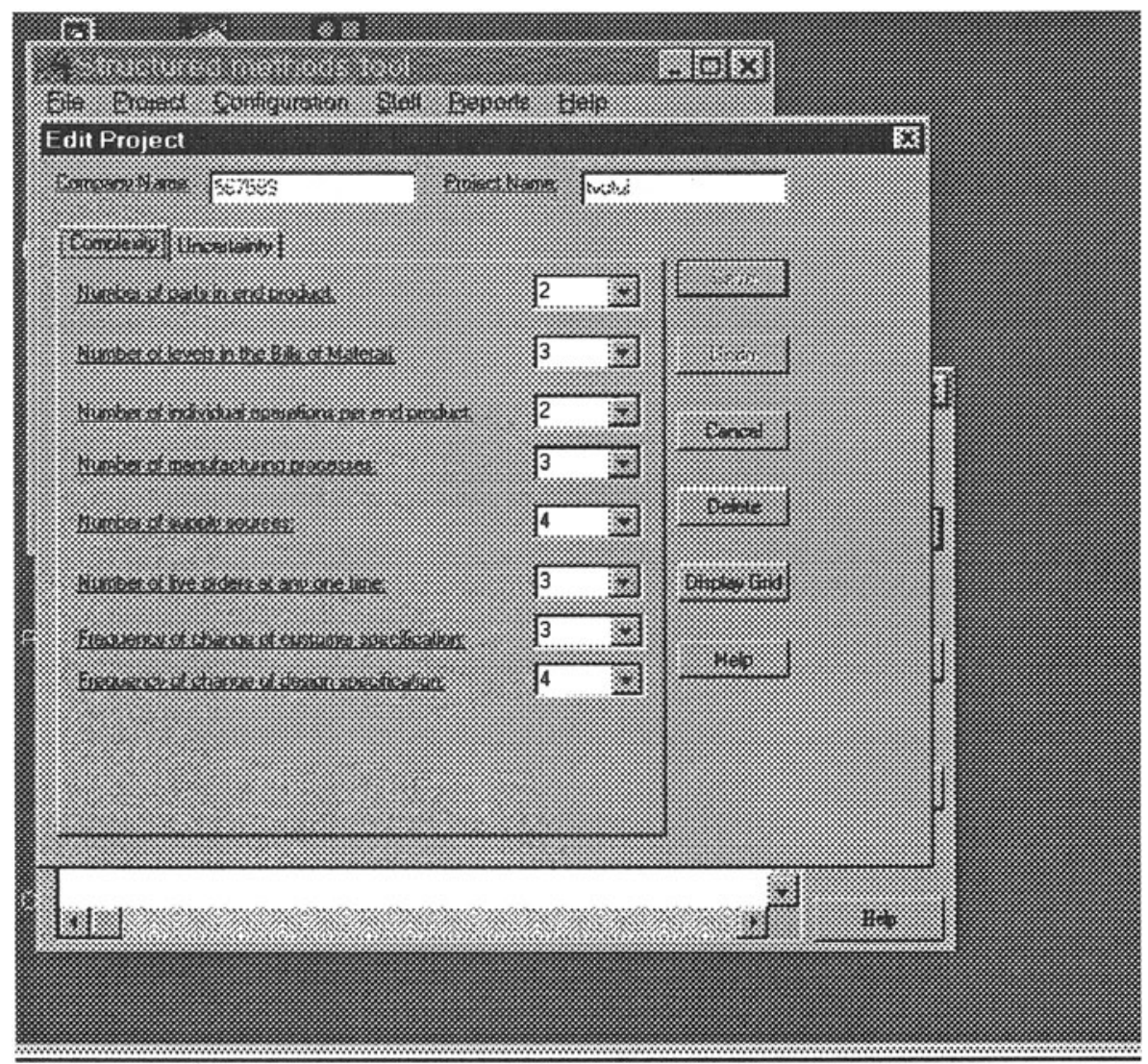

Figure 3: Business Analysis Module User Interface

\section{CONCLUSIONS}

The first phase of the research confirmed the view that very little use of structured methods and tools was made by SMEs in the North of England. Yet the need for improved information systems was seen to be critical to their business success. Frequently SMEs were relying upon packaged software supplied on the advice of vendors who could not claim independence. In a number of cases the packages were inappropriate and expensive.

The SMEST tool was developed to explore how effective a simple approach to define requirements in an uncomplicated manner without having to deal with the complexity associated with the modelling techniques could be. 
Its main advantage is that relevant information is entered in a structured, easy-toanalyse form. This ensures uniform, complete documentation. The incorporation of a user-friendly interface offers a comfortable means of creating and modifying the necessary information.

Whilst the method and tool should be viewed as prototype only at this stage, discussions have started with colleagues at Bradford and Plymouth Universities to discuss the feasibility and desirability of extending the work. We wish to acknowledge the support of the EPSRC for this work.

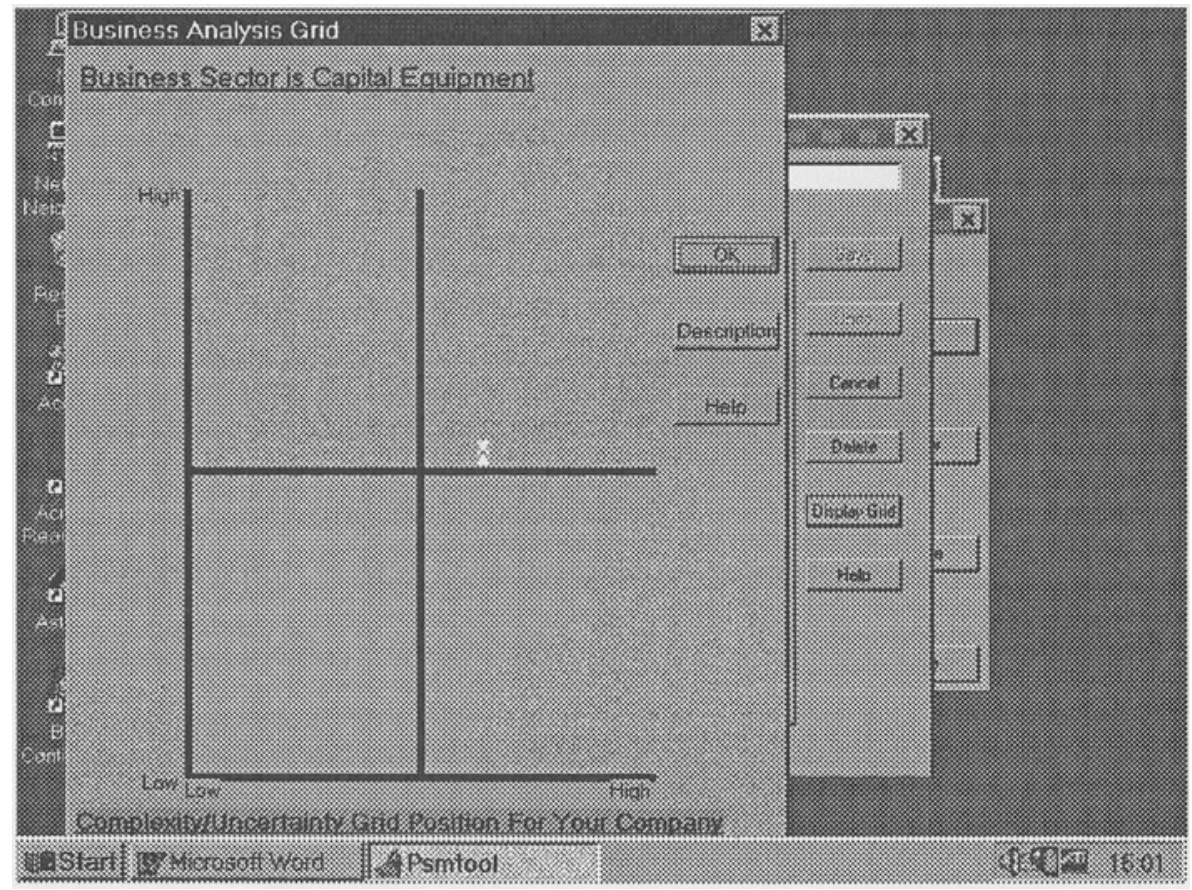

Figure 4: $\quad$ Business Analysis Grid Screen

\section{REFERENCES}

Little D and Kenworthy J K (Dec 91 - Feb 95), Planning and Scheduling Reference Models for different industrial sectors. EPSRC, GR/H20473. 
Little D, Gavin C J, Hodgson N and Guenaoui D (1997), Survey of SME information systems planning and operation. CONTROL, Institute of Operations Management, Vol 23 No 5, June, 17-20.

Little D. and Gavin C J (Sep 1994-Nov 1997), Requirements for increased use of Software Engineering methods and tools in Manufacturing Industry. EPSRC GR/K40901.

Jordan, P., Browne, J. and Jagdev H.S (1995), A production Planning and Control Architecture for Small Manufacturing Enterprises, The IFIP WG 5.7 Conference on concurrent engineering, Seattle, USA,

\section{BIOGRAPHY}

David Little worked in industry after graduating from Loughborough University with GEC, A. Reyrolle and Molins Ltd, where he started as a project engineer on System 24 (the world's first FMS) and ended up as a senior manager in their Spares Division. He moved into higher education at Huddersfield Polytechnic Business School. Leaving to undertake research at Liverpool University, he became a senior lecturer and Sub-Dean in the Faculty of Engineering and returned to the University of Huddersfield as Professor of Manufacturing Systems in January 1996. He is a past-president of the Institute of Operations Management.

Carl Gavin graduated with first class honours in computer science at Liverpool University and then completed his $\mathrm{PhD}$ there researching into the application of CASE methods and tools within manufacturing industry. He moved to the University of Huddersfield as a Research Fellow before returning to Liverpool to take up a lecturing post. He recently joined the Sema Group as a managing consultant specialising in IT applications within manufacture.

DjelloulGuenaoui gained his Ingeniorat at Oran University and then undertook research in software engineering for his $\mathrm{PhD}$ at Sheffield University. He then worked in a software house using Borland's Delphi for applications development. He was involved in the project as a Research Fellow at the University of Huddersfield and is now researching at Leeds University.

Chris Keller-Jackson successfully completed the CIM masters degree at the University of Huddersfield and joined Joseph Sykes of Lindley, a wire drawing firm, to support the development of their production control systems. 